\title{
A Arte de Ensinar Matemática com Uso das Tecnologias Digitais
}

\author{
Antonio Neres Oliveira ${ }^{1}$ \\ ${ }^{1}$ Licenciatura em Ciências Naturais - Universidade Federal do Maranhão (UFMA) \\ Imperatriz - MA - Brazil \\ aneresoliveira@gmail.com
}

\begin{abstract}
The present study shows the results of a practical experiment with a specific aim of observing the role of digital technologies in the development of mathematical creativity in the light of the knowledge construction theory. From a case study, an analysis was made of the results of an empirical intervention with 20 first year students of a state public school. The partial results showed the potential of creativity for the teaching and learning of Mathematics.
\end{abstract}

Resumo. O presente estudo mostra os resultados de um experimento prático com o objetivo especifico de observar o papel das tecnologias digitais no desenvolvimento da criatividade matemática à luz da teoria da construção do conhecimento. A partir de um estudo de caso, foi feita uma análise dos resultados de uma intervenção empírica com 20 alunos do primeiro ano de uma escola pública estadual. Os resultados parciais mostraram o potencial de criatividade para o ensino e aprendizagem de matemática.

\section{Introdução}

O estudo faz uma reflexão acerca do uso das Tecnologias Digitais de Informação e Comunicação - TDIC no apoio e desenvolvimento da criatividade em Matemática. Com esse intuito, realizou-se uma discussão geral sobre os aspectos do fenômeno criativo alinhada ao ensino de Matemática.

Nessa perspectiva, argumenta-se sobre o fenômeno da criatividade matemática, ressaltando as contribuições teóricas atuais e a primazia da sua aplicabilidade no ensino e aprendizagem de Matemática. Além disso, fez-se uma análise de um estudo empírico, com a participação voluntária de 20 alunos do primeiro ano do Ensino Médio de uma escola pública estadual.

\section{Contribuições Teóricas ao Estudo}

O conjunto de interseção que unifica as Tecnologias de Informação e Comunicação (TIC) e a Matemática, segundo Morais et al (2010), são os pilares da evolução científica e tecnológica experimentado pela humanidade. Nesse cenário, integrar o ensino com as tecnologias, como resposta aos desafios da aprendizagem da disciplina, pode ser o marco 
VII Congresso Brasileiro de Informática na Educação (CBIE 2018)

Anais do XXIV Workshop de Informática na Escola (WIE 2018)

de um novo processo para o ensino e aprendizagem de Matemática (OLIVEIRA et. Al., 2016).

Mann (2006) sugere aos professores e pais que ajudem seus alunos e filhos com atividades desafiadoras. E para tal, devem desenvolver tarefas e experiências significativas para fomentar a compreensão de técnicas por meio de instrução e modelagem, estabelecendo um ambiente criativo que incentive o enfrentamento de riscos e curiosidades.

Em relação a essa discussão, Paiva et al (2014) argumentam que, em ambientes tecnológicos, os alunos são levados a refletir sobre as implicações matemáticas de suas ações, uma vez que abre uma gama de opções para experimentar novas ideias de tal maneira que seria impossível apenas com o uso de papel e lápis.

Türegün e Conde (2014), em suas conclusões preliminares sobre o papel da tecnologia e da criatividade no desenvolvimento da capacidade em resolver problemas, inferiram, a partir de um conjunto de respostas produzidas por um grupo de alunos, sobre a necessidade de proporcionar ambientes ricos e oportunos para o engajamento de professores a serviço de atividades criativas voltadas à resolução de problemas matemáticos.

Lubart (2007) também congrega com essa linha de pensamento, entretanto, adverte sobre o uso puramente técnico dos softwares educacionais que limitam a flexibilidade em detrimento da rentabilidade do produto. Nessa perspectiva, Papert (2010) alerta para os riscos da capitalização do ensino pela subversão da tecnologia à tecnicidade, ou seja, a lógica do mercado pode, na eterna busca pela produtividade, corromper boas ideias em favor da sistematização e rotinas técnicas.

Em relação às preocupações precedentes do parágrafo anterior, Royo e Joaquim (2014) argumentam que o papel das ferramentas tecnológicas, assim como dos ambientes virtuais de aprendizagem, não se precipita em substituir o professor, mas configura-se em dar maior fluidez ao ensino, que visa criar um contexto que promova o desenvolvimento e compreensão do conhecimento matemático.

\section{A Experiência Didática}

O estudo empírico incidiu sobre as soluções das situações-problemas apresentadas aos alunos. As conclusões evidenciadas a seguir levaram em consideração os trabalhos de cinco (05) alunos concludentes do estudo, com olhar para a produção individual e do grupo.

$\mathrm{Na}$ primeira fase do desafio, solicitou-se aos alunos que achassem as relações entre as áreas e os perímetros de um disco de dados e sua capa. Nessa perspectiva, acreditou-se que o disco tinha a forma de um círculo e a capa de um quadrado, mesmo sabendo que existem capas de outros formatos. Porém, tais discordâncias não comprometeram o entendimento da questão.

Para realizar as tarefas sugeriu-se o uso do programa de geometria dinâmica GeoGebra. Os protocolos de construção do software e as observações dos acessos dos alunos na turma virtual e, em loco (presencial), forneceram os dados para as observações e conclusões do pesquisador. 
VII Congresso Brasileiro de Informática na Educação (CBIE 2018)

Anais do XXIV Workshop de Informática na Escola (WIE 2018)

O grupo envidou esforços para construir um círculo inscrito dentro de um quadrado. A construção demandou ao pensamento divergente, pois havia várias maneiras para a realização da tarefa. A fluidez das ideias foi um dos pontos altos das construções, e nesse aspecto, notou-se uma variedade de construções (flexibilidade), desde as mais toscas as mais elaboradas e originais. O exemplo abaixo (Quadro 1) mostra um resumo de uma das situações (respostas) que mais chamou atenção.

Quadro 1. Produção didática do aluno. Fonte: arquivo pessoal, 2014.

\begin{tabular}{|l|l|}
\hline Produção do aluno & Observação do Pesquisador \\
\hline $\begin{array}{l}\text { Quadrado de lado: } 1 \\
\begin{array}{l}\text { Airea do círculo: } 3 / 4 \text { da área } \\
\text { do quadrado; }\end{array}\end{array}$ & $\begin{array}{l}\text { A princípio, não entendi a resposta do } \\
\text { participante do estudo. Então, perguntei ao } \\
\text { mesmo, como chegou a tal conclusão. Depois } \\
\text { de suas explicações, ficou claro que o aluno } \\
\text { imaginou o círculo sem os quatro cantos do } \\
\text { quadrado. Pensou que a soma dessas partes } \\
\text { resultaria em um quarto do quadrado, então } \\
\text { concluiu, que a área do círculo valia } 3 / 4 \text { da área } \\
\text { do quadrado. }\end{array}$ \\
\hline
\end{tabular}

A resposta não está correta, pois sabemos que a área de um círculo inscrito em um quadrado de lado 1 , vale aproximadamente $0,785\left(\pi r^{2}\right)$ e não $0,75(3 / 4$ de 1$)$, como pensou o aluno. No entanto, a resposta mobilizou estruturas cognitivas, na medida em que o aluno buscou caminhos diferentes dos padrões já consagrados pelas ciências matemáticas. Nesse exemplo, pode-se notar o potencial das tecnologias alinhado a uma situação problema para desenvolvimento da criatividade em Matemática.

A segunda fase das situações didáticas apresentadas aos alunos, a partir de um problema semiaberto, desafiou-os a registrar em um disco de 1 Megabytes (MG) com músicas, filmes e fotos. O problema estabeleceu algumas condições, tais quais relacionadas à reserva de $1 / 4$ dos dados para outras aplicações. Inicialmente, os esforços concentraram em desenhar círculos divididos em partes iguais. Então, a maioria das respostas destinou 256 kilobytes $(\mathrm{KB})$ em cada uma das partes.

Aplicando um procedimento aritmético já conhecido, um dos participantes conseguiu uma resposta que parecia satisfatória para a questão. Dividiu 768 por 3; do quociente obtido, multiplicou, respectivamente, pelos pesos 1, 2 e 3, e obteve como resultado as proporções: 256, 512 e 768. Foi solicitado pelo pesquisador que se realizasse a soma das partes encontradas $(256+512+768)$ para mostrar que a resultante excedia 0 todo.

Nas outras tentativas subsequentes, para acomodar os dados em diferentes partes, mesmo não chegando a uma resposta precisa, assimilou a noção de proporção direta, pois cada parte diferente de dados deveria adapta-se as distintas porções gráficas. O pesquisador acredita que a fluidez das ideias gráficas usadas para se estabelecer uma proporção adequada dos dados, pode ter levado a resposta ao problema que fora resolvido da seguinte forma.

Com o mesmo procedimento aritmético mostrado anteriormente; dividiu 768 pela soma de $(1+2+3=6)$ para obter o quociente 128 , que multiplicado por 1,2 e 3 , respectivamente, resultou em 128, 256 e 384. A partir das respectivas proporções, o grupo 
VII Congresso Brasileiro de Informática na Educação (CBIE 2018)

Anais do XXIV Workshop de Informática na Escola (WIE 2018)

constatou que eram necessários setores de proporções diferentes, e que foram obtidos através de uma regra de três simples.

A atividade possibilitou aos alunos o desenvolvimento do pensamento divergente, na medida em que os conduziu a caminhos distintos na busca por respostas. Conforme Alencar (2010), o pensamento divergente é um dos elementos fundamentais para a promoção da criatividade.

A terceira parte das situações didáticas objetivou compreender a realização dos alunos na primeira fase, que está relacionada aos conhecimentos físico e lógico matemático. Nesse aspecto, não houve muita dificuldade no preenchimento da tabela. A cooperação contribuiu para a realização das tarefas pela socialização dos resultados.

A quarta fase das situações-problemas revelou-se, no contexto da flexibilidade e das novas situações não previstas, grande potencial para o campo da investigação, conforme esquema abaixo (Quadro 2):

Quadro 2. Produção didática do aluno. Fonte: arquivo pessoal, 2014.

\begin{tabular}{|c|c|c|}
\hline Produção do aluno & & Observação do Pesquisador \\
\hline 16 & $\begin{array}{l}\text { Diagonal }=l^{2}+l^{2} \text { ou } d=l \sqrt{2} \\
\text { Aluno: Professor as próximas diagonais } \\
\text { são: } 4 \text {; raiz de } 32,8 \text { e raiz de } 128\end{array}$ & $\begin{array}{l}\text { Antes de chegar a esse resultado o } \\
\text { aluno construiu vários quadrados, } \\
\text { com as dimensões } 1,2,3,4 \ldots \text { n. } \\
\text { Então, a partir do quadrado de lado } \\
\text { dois, sem efetuar os cálculos, } \\
\text { concluiu as próximas diagonais. } \\
\text { Solicitei ao aluno que explicasse } \\
\text { suas afirmações. Em suas } \\
\text { ponderações, afirmou: "na } \\
\text { realidade, os próximos lados do } \\
\text { triângulo retângulo são expressos } \\
\text { pela diagonal anteriormente } \\
\text { encontrada, ou seja, são sempre } \\
\text { lados de um quadrado. A partir daí, } \\
\text { ficou fácil perceber os resultados". }\end{array}$ \\
\hline
\end{tabular}

A partir de um conjunto de experimentações (fluência) um dos alunos previu as próximas diagonais de um quadrado de lado dois sem fazer uso da regra $\mathrm{d}=\left({ }^{1} a d o * \frac{\sqrt{2}}{1}\right)$. Notou as relações da raiz quadrada com as potências de base dois, assim como os resultados das diagonais alternadas.

A última fase fez um apelo à criatividade dos alunos no quesito elaboração. Entretanto, apenas um dos alunos conseguiu combinar as diferentes figuras dos problemas anteriores para construir algo novo. O pesquisador atribui esse fato às condições impostas ao problema.

\section{Considerações Finais}

A experiência didática fez uma revisão da literatura sobre criatividade e do uso das tecnologias digitais para o florescimento da criatividade em Matemática, assim como aponta algumas conclusões sobre uma investigação empírica com alunos do primeiro ano do Ensino Médio de uma escola pública estadual. 
O objetivo da investigação, no campo da revisão bibliográfica, visou dar uma contribuição ao estado da arte sobre o uso das tecnologias para promover a criatividade em Matemática. No plano das investigações, a revisão bibliográfica mostrou uma escassez de obras em nível nacional sobre esse tipo de pesquisa, entretanto, em nível internacional observa-se uma variedade de artigos e livros sobre o tema.

No quesito experimental, objetivou conhecer aspectos da construção do conhecimento matemático e da criatividade, alinhados as situações-problemas mediadas pelas tecnologias digitais. Nesse aspecto, o experimento, mesmo que ainda exploratório, mostrou que as TDIC cooperam para a fluidez e a flexibilidade do pensamento. Mann (2006), aponta que a criatividade em Matemática é medida pela flexibilidade, fluência e originalidade dos problemas construídos pelos participantes.

\section{Referências}

Alencar, E. M. L. S.; Faria M. F. B.; Fleith, D. S. (Orgs.). (2010). "Medidas de criatividade: teoria e prática". 1. ed. Porto Alegre: Artmed, v. 1, p. 160.

Lubart, T. (2007). "Psicologia da criatividade”. Tradução de Márcia Conceição Machado Moraes. Porto Alegre: Artmed.

Mann, E. L. (2006). "Creativity: The Essence of Mathematics". In. Journal for the Education of the Gifted, v. 30, n. 2, p. 236-260.

Morais, C.; Pereira, R.; Miranda, L. (2010). “Aprender matemática em ambientes online”. EDUTEC, Bilbao: Universidad del País Vasco, <http:/hdl.handle.net/10198/4756>.

Oliveira, A. N. et al. (2016). "O uso das Tecnologias Digitais no apoio a construção do conhecimento matemático". In: Anais do XXII Workshop de Informática na Escola, Uberlândia-MG.

p.

191-200,

$<$ http://www.brie.org/pub/index.php/wie/article/view/6616>.

Paiva, J.; Amado, N.; Carreira, S. (2014). "The Role of Peer and Computer Feedback in Student's Problem Solving". In. Technology, Creativity and Affect in Mathematical Problem Solving, p. 59.

Papert, S. (2010). "A máquina das crianças: repensando a escola na era da informática”. Tradução de Sandra Costa. Porto Alegre: Artmed.

Royo, M. P.; Giménez, J.; Montillivi, I. N. S. (2014). "Electronic Forums: An Added Value When Solving Initial Algebraic Problems". In. Technology, Creativity and Affect in Mathematical Problem Solving, p. 84.

Türegün, M.; Conde, L. (2014). "The Role of Using Technology and Creativity in Developing Positive Dispositions Toward Mathematical Problem Solving". In: Technology, Creativity and Affect in Mathematical Problem Solving, p. 108. 